\title{
THE ESTATE SURVEYORS AND VALUERS AND THE MAGIC NUMBER: A POINT ESTIMATE OR A RANGE OF VALUE?
}

\author{
Bioye Tajudeen ALUKO ${ }^{1}$, C. A. AJAY1 ${ }^{2}$ and Abdul-Rasheed AMIDU ${ }^{1}$ \\ ${ }^{1}$ Department of Estate Management, Obafemi Awolowo University, He - Ife, Nigeria \\ 2 Faculty of Environmental Design and Management, Obafemi Awolowo University, Ile - Ife, Nigeria \\ E-mail: amidrasheed@yahoo.co.uk
}

Received 23 February 2004; accepted 8 September 2004

\begin{abstract}
Property value is imprecise because of the imperfection of the property market. But, estate surveyors and valuers in Nigeria traditionally have continued to express this value as a single amount. This paper, therefore, attempts to examine the rationale behind this approach and the attendant problems associated with it. Besides, the paper, amongst other things, recommended that estate surveyors and valuers should expand the scope of their services beyond the confines of point estimates so that clients be informed as to the amount of possible deviation and the magnitude of risk in the value estimate through the adoption of statistical techniques.
\end{abstract}

KEYWORDS: Point Estimates; Imprecision; Market Imperfections; Range of Value; Statistical Techniques

\section{INTRODUCTION}

The estate surveyor and valuer is an analyst of human behaviour in the property market whose main function is to estimate or predict the value of an interest in land. This estimate or opinion of value could help property owners (corporate, institutional, financial or individual) solve a myriad of problems including inheritance, asset sharing, asset allocation or relocation, property performance measurement, privatization and commercialization of assets, nationalization, property sales, purchases and so on. An issue which has remained a 'mystery' or myth' in the profession and to clients is how to explain the valuation process and how this is translated to a figure of value; thus, the phrase 'magic number'.

The process of estimating price or the magic number in the market place is often referred to as valuation. Yet, such an estimation will be affected by uncertainties. Uncertainty in the comparable information available; uncertainty in the current and future market conditions and uncertainty in the specific inputs for the subject property. This uncertainty, as described above, relates to valuation accuracy and not the variance in valuations produced by different valuers for the same property. It is expected, therefore, that the former uncertainties will translate into an uncertainty with the output figure, the valuation. This valuers' errors in price prediction arise from both random variation in observed prices of comparable sales used as evidence and the mistakes in the valuer's model of price differences. For instance, any individual property at a particular point in time have, possibly, different prices due to different circumstances of sale, differing buyer preferences, different buyer information sets or other factors. Kummerow referred to this variation as "random error" Moreover, measurement and misspecification errors, also known as "interpretative errors" (Aluko, 1998)

\section{International Journal of Strategic Property Management \\ ISSN 1648-715X \\ http://www.vtu.lt/english/editions}


in the price differences model also tend to increase as we add more comparable sales (Aluko, 1998; Kummerow, 2002; Kummerow and Galfalry, 2002; and, French and Gabrielli, 2003). So there is an error trade-off and larger samples may not help us get more precise estimates.

But, estate surveyors and valuers in Nigeria traditionally have continued to express this magic number as a single amount. These point estimates falsely imply absolute accuracy albeit in an imperfect real estate market. Real estate assets are heterogeneous and non-du-plicative, that is, their characteristics vary. The valuer's job is to understand which characteristics increase or decrease buyers' willingness to pay in the case of a particular property and by how much; instead of looking up prices in the financial press, as one would do with a share or commodity price. This is because they are no wiser than the market, and the market is represented by selling prices. In other words, if data were readily available (as in the case of shares and stocks), valuations would not be needed. If at the other extreme, data were totally lacking, valuations would be impossible (Aluko, 1998).

As evident from above, it is odd that in property markets, valuers have been trained to avoid forecasting future prices (future each flows), when in finance markets this is the key to analysts' evaluation of investments. Property valuers relegate themselves to the relatively unrewarding task of substituting of the stock price ticker or financial press. This passive reporting of recent transaction, without opinions about whether the investment is properly priced or any bets about whether it is worth owning, in terms of future performance, adds less value than share market "valuations". Finance theory compels forward-looking valuation. Current markets may misprice and for values to perpetuate or magnify mispricing by relying only on recent "bubble" or "bust" sales abrogates a professional responsibility to help make markets more efficient and valuation products more valuable to clients. Thus, estate surveyors need to either predict or estimate most probable selling price, depending on the level of confidence.

This becomes necessary as the propensity of equally well qualified valuers to arrive at substantially different value conclusions for the same property has been noted both inside and outside the profession (Smith, 1986; Ferguson, 1988; Hager and Lord, 1985; Brown, 1985; 1991; and, Aluko, 1998). Therefore, if valuations should continue to serve as invaluable contributions in the decision-making processes associated with real properties, in our dynamic, ever complex property market, our numerous clients have to be informed as to the amount of the possible deviations and the magnitude of risks in the value estimates.

Although, most clients are only interested in the final figure of value, it will be an abdication of our professional responsibility providing estimates and predictions without qualifying the confidence level through the use of probability distributions. It is the objective of this paper, therefore, to demonstrate that property value estimates are imprecise due to market imperfection, and are associated with risks that are better expressed as a range rather than point estimates through the use of statistical techniques. To achieve this objective, this paper examines in turn the genesis of the imprecision of point estimates, its implication on valuation accuracy, the factors responsible for this and the relevance of statistical analysis as a way of qualifying the point estimates expressed by estate surveyors and valuers to enhance their reliability in an imperfect real estate market.

\section{CONCEPTS OF VALUE}

Central to any valuation assignment is the concept of value. Because value to many people means either market value or price (value in exchange) and worth (value in use), there is often confusion in the minds of recipients of valuations as to the meaning of the fig ure set out in the valuation report. 
The Royal Institution of Chartered Surveyors (RICS) in the RICS Manual of Valuation and Appraisal (2000). which is in use in Nigeria, recognised these definitions of value as explained below:

Price - is the actual observable exchange price in the open market,

Market Value - is an estimation of the price that would be achieved if the property were to be sold in the market,

Worth - is the specific investor's (or occupier's) perception of the capital sum that he would be prepared to pay (or accept) for the stream of benefits that he expects to be produced by the property.

And, closely related to worth or use value (value - in - use) is investment value. It is the value of an investment property to a particular investor based on his or her investment requirements. For instance, IVSC (2000) defines investment value as "the worth of a property to a specific investor based on available financing, desired rate of return, risk, and other assumptions unique to the investor". Investment value is, therefore, value to an individual (subjective), rather than value in the market place (objective)

Market value, in contrast, must be independent of any isolated (spot or investment) value judgement if it is to have meaning. It must reflect only the value (spread or range of) judgements of individuals collectively and to the extent that those judgements are informed about and expressed in the market behaviour. Hence, in perfect market where any individual has access to the same information as all others in the market, market value, market price and worth (investment value) should coincide. However, in a market where access to information is not uniform, such as the property market, it is more likely that the figures as related to the above concepts will diverge (Peto, French and Bowman, 1996).

But, the valuers' role is to observe and predict market value under prevailing market conditions where clients make their moves. This real estate market is imperfect or uncertain and, market value is represented by selling prices. In determining market value, the model adopted should mirror the thought process of the investors/players in the market. Accordingly, price is a figure at which the market is in balance, at the moment that a transaction is completed. It is a snapshot in a dynamic market. Consequently, valuation can be defined as an estimate of the possible price distribution for the subject property as of a given date; and, so include random variation. In fact, valuation exists as a field because there is uncertainty on the part of potential buyers, investors, sellers and others in the property market. This stems in part from the complex nature of product (the real estate itself), and from the uninformed, imperfect, complex nature of the real estate market. Therefore, in reaching his or her judgement, uncertainty will arise in valuer's mind, either due to the difficulty of assessing the market itself or in assessing how the market would price the peculiarities of the subject property. The valuation is, for this reason, actually a range based on probability. And, to simply provide a market valuation figure without placing hat figure into some economic context is akin to abdicating professional responsibility.

Therefore, using a statistical value definition that builds in estimates of errors gives valuers a simple way to report the total uncertainty in markets plus their own mistakes in reading markets (Kinnard, Jr., 2001; French, 1997; 1998; and Kummerow, 2002). A strong authority for the foregoing can be derived from the works of Ratcliff $(1972 b ; 1979)$ who originally proposed, and demonstrated how the three concepts of value above are interrelated and, are impacting upon real estate decisions. These concepts which correspond directly to the definitions of valuation adopted by the RICS, as earlier given above, are represented by symbols below:

$\mathrm{V}_{\mathrm{s}}$ - Subjective value to owner (investment value);

$\mathrm{V}$ - Market value;

$\mathrm{V}_{\mathrm{t}}$ - Price at which property is sold. 
As indicated above, in a buy/sell decision, all other things remaining the same, a vendor/seller will take a decision to sell at a point where the price in the market $\left(\mathrm{V}_{(>)}\right)$is equal to or greater than the calculation of worth or investment value $\left(\mathrm{V}_{\mathrm{s}}\right)$. Conversely, a rational buyer, having formulated his $\mathrm{V}_{\mathrm{s}}$ for the property, will make decision to buy if the price in the market $\left(\mathrm{V}_{\mathrm{b}}\right)$ is equal to or below his/her assessment of the present worth (investment value $(\mathrm{V})$,$) ; that is \mathrm{V}_{\mathrm{b}}<\mathrm{V}_{\mathrm{s}}$ and $\mathrm{V}_{\mathrm{b}}<\mathrm{V}_{0}$. Through negotiation, a transaction price, $V_{t}$, will be agreed upon. This mechanism is represented diagrammatically (see Ratclifif, 1972b, plOl and Whipple, 1990, pl8) (see Figure enclosed below).

As shown below, given that price is a function of supply and demand, the valuer's/pricer's task is to assess the forces of supply and demand and determine the striking price $\mathrm{Vt}$, the most probable selling price. Thus, valuation is the prediction of $\mathrm{Vt}$ and, is represented by $\mathrm{Vp}$. Two conclusions literally emerge from the diagram above. First, it shows that $\mathrm{Vp}$ is bedeviled by uncertainty and should therefore be expressed in probabilistic terms. And, second, it illustrates how $\mathrm{Vt}$ is the outcome of a market behavioral process, the outcome which varies with the different parties, even for the same property, in the market (Whipple, 1990). This is so because the market place and its participants make value. Perhaps, further plausible reasons accounting for uncertainty or providing for variation/range in value estimates are as given by Peto, French and Bowman (1996). These are:
- The pressure on and/or the desire of the vendor to sell.

- The pressure on and/or the desire of the purchaser to buy.

- The availability of the alternative stock.

- The availability and pricing of other investment options.

- The availability and pricing of finance

- Taxation.

- General market sentiment, including expectations.

However, in spite of the above, there is still confusion about whether valuers' role is to observe and predict market prices under prevailing market conditions or alternatively to define and create price estimates under a set of standardised assumptions. These arguments are further examined in the next section below with a view to further providing theoretical foundation for the main thrust of this paper.

\section{VALUE ESTIMATION V PRICE PREDICTION?}

The root cause of the foregoing problems concerning the lack of precision of valuation theory, unlike economic theory, could be traced to differing concepts of value amongst estate surveyors and valuers (Smith, 1977; 1986; Skyes, 1984; and, Downs, 1991). With regard to value estimation, it appears that are two schools of thought. The first is based on the normative definition of market value. Most market value definitions in this school use such

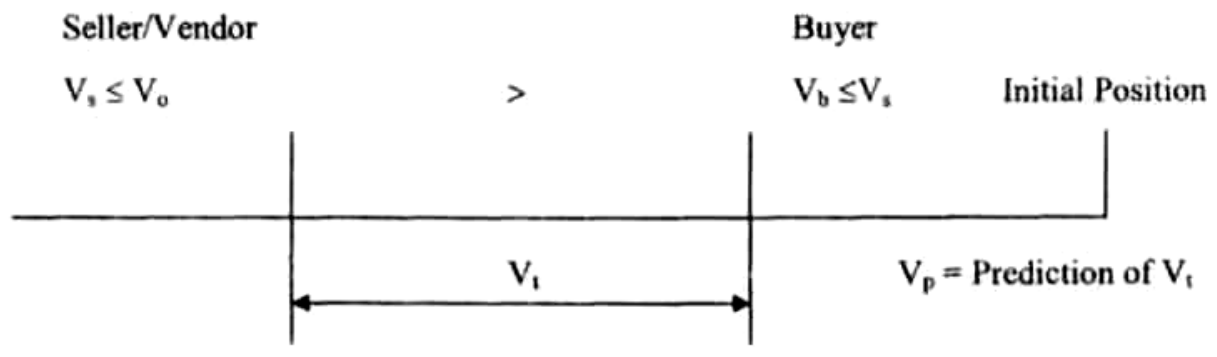


qualifying terms as "expectable" "most reasonably expected", "might reasonably be expected" and "expected selling price" and are premised on the assumption of certain idealised competitive conditions; namely, that a property must be exposed to the market for a "reasonable" period of time, there must be many potential buyers and sellers, each market participant must be informed and must act in an economically rational manner, and there must be "conditions requisite to a fair sale", that is, neither the buyer nor the seller can be under coercion or undue pressure. Furthermore, payment in a transaction is assumed to be consistent with the standards of behaviour of the market (NIESV, 1985; and, TIAVSC, 2000). The estate surveyors who prefer the above view of market definition are described as "value estimators" (Lusht, 1981, and, Aluko, 1998). This viewpoint is normative in context and is concerned with the estimate of what would or should occur in a reasonable efficient, competitive market.

The other school of thought takes into account reality of real estate market, where valuation clients must make their moves and whose characteristic is notoriously imperfect. The product traded is highly differentiated, market information is incomplete and often unreliable, individual market decisions are not always prudent or rational, and buyers and sellers are not always willing. These imperfections make it impossible for the valuers to predict with absolute certainty what value the subject property would bring if offered for sale in today's market. Thus, a minority of estate valuers prefers to describe themselves as "price predictors" (Lusht, 1981; 1983, Reenstierna, 1983, and Ratcliff, 1975). The most widely used definition reflecting this preference states that "market value is the most probable selling price" (Ratcliff, 1975). As Smith (1977) points out, Ratcliff's concept imposes no requirements or constraints on either the market or the market participants. If a property is most likely to sell at an inflated price to a poorly informed purchaser with all cash, that price would con- stitute the properties market value. So would the prices obtainable in a distress sale, in a depressed market, or from a needy neighbour, if those were the facts associated with the most likely sale. This is a positive definition and is based on prices of observed transactions. This concept is widely gaining acceptance as it infers that the actual market conditions at the time of valuation are taken into account.

These viewpoints (value estimation and price prediction) rarely agree and, have received widespread attention over an extended period and the current situation is at best an uneasy truce especially as related to either valuation accuracy or variance (Lusht, 1983; Vandell, 1982; Downs, 1991; Roberts and Roberts, 1991; Parker, 1998; Bretten and Wyatt, 2001; and Bowles, McAllister and Tarbert, 2001). For instance, the traditional definitions, as explained above under the two schools of thought, create confusion about whether valuers' role is to observe and predict market prices under prevailing conditions or alternatively to define and create price estimates under a set of standardised assumptions. There is, therefore, lack of clarity and precision in the value definitions as well as the existence of disparities between the definitions and standard economic and finance theories of how prices are determined in markets (Albritton, 1980; 1982; Whipple, 1995; and Kummerow, 2002). Nevertheless, it is noted that positive definition allows valuers the freedom to look at actual market conditions, suggesting a checklist of issues to describe in characterising the transaction. It assumes market prices are revealed by market transactions, but that valuations can benefit by taking into account deviation from assumptions required for market efficiency in the subject case. It is evident that we customarily treat price as a random variable, that is, price has a distribution or variability described by an error term. Professor Colwell remarked, "there is a distribution of potential selling prices for any subject property to be appraised" (Colwell, 1979: 106) An intuitive understanding of price variation might come from things people say 
like "he got a good price" or "it sold cheap", suggesting they have in mind a distribution of possible prices a property might have sold for. The foregoing argument, if accepted, require estate surveyors and valuers to be familiar with basic statistical concepts like distributions, probability and descriptive statistics and, therefore, has implications for real estate educators. Thus, the possible price distribution to be reported in a valuation report is simply the relative frequencies of possible sales prices that might occur on the valuation date. Many academic writers (including, for example, Ratcliff, 1972b; 1975; Colwell 1979; Miles 1980; Albritton, 1980; 1982; Korpacz and Marchitelli, 1984; Shlaes, 1984; Reenstierna, 1985; Whipple, 1990; 1995; Kummerow, 2000; 2002; Kum-merow and Galfalvy, 2002; and, French and Gabrielli, 2003.) for a very long time now, have been proposing a statistical definition of value that has the following four clauses.

- Estimates of parameters of the subject property's possible sale price distribution.

- Estimates of errors in the parameter estimates.

- Forecasts of the stability of the estimates over a relevant future period.

- Statements of assumptions about the circumstances of sales that may influence the possible price distribution including legal rights valued, date of sale, method of sale, time on the market, finance, probable uses of the property valued, probable buyers and motives/ knowledge of buyers and sellers.

As both Carsberg (2002) and Mallinson (1994) suggest in their respective recommendations (15 and 34 respectively), the aim is to establish an acceptable method by which uncertainty could be expressed in a uniform and useful manner. In its simplest form, this would be the mean expectation of value (based on the varying probability of the inputs) plus the variation pertaining to that value within the one valuation (Not variance of value between different valuers). This is effectively the best estimate plus standard deviation. In support of the above proposition, French and Mallinson
(2002) argued that there are six items of information that must be conveyed to a client in a valuation report as follows.

1. the single figure valuation,

2. the range of the most likely observation,

3 . the probability of the most likely observation,

4. the range of higher probability,

5 . the range of $100 \%$ probability,

6. the skewness of probabilities.

A further option, as suggested by Mallinson (1994), which was considered by French (1995) and developed by Adair and Hutchison (2001), although similar to an earlier study by Miles (1980), is to provide a simple risk score. The premise in this case is that the valuation could be provided as an indication of the risk of variance (say '1' for a low risk of variation to '4' for high risk of variation). Nonetheless, whichever approach is more superior to another, the foregoing is a representation of the uncertainty of the output. And the figures generated are dependent upon input benchmarks and the uncertainty relating to each of those variables.

We can test the efficacy of the above positions by examining, further, the two schools of thought as already identified. For example, Webster's dictionary (1995) says that to estimate is to judge tentatively or approximately the value, worth or significance of and that to predict is to "foretell on the basis of observation, experience, or scientific reason". We should, perhaps, note the distinction. Prediction implies a more objective justification. Estimation is relatively subjective, based more on opinion, and implies less precision. Then, based on the imperfect nature of the market, one generally will have more confidence in a prediction than in an estimate. In practice, vaiying degrees of data quantity and quality are encountered, and these differences introduce uncertainties in the relative confidence the valuer has in the final value arrived at. Estate surveyors must frankly admit that their predictions are fraught with various degrees of dependability. Therefore, rather than point estimates, some academic authors and profes- 
sionals, as noted above, have argued that clients should be given the opportunity of probability qualification to the valuation figure in his report.

\section{IMPLICATION OF FOREGOING DISCUSSIONS ON VALUATION ACCURACY}

The value of property is a foundation of business and economic prosperity, but, unlike other investments, there has been little or no information available on transaction based prices. Consequently, the investment performance of property has depended upon 'valuation' of the open market value of each property. Because of importance of valuations to the property performance measurement, the question of accuracy of valuations in satisfying clients' objectives, through the adoption of point estimates, has generated a lot of controversies.

During the 1970s, criticisms from both inside (for example; Wood, 1972; and Greaves, 1972) and outside (Greenwell and Co., 1976) the valuation profession were voiced in the U.K. Valuations of the assets by different valuation firms showed substantial discrepancies or errors. This has continually been experienced in Nigeria by estate surveyors, particularly in the recent past and, now, in the valuation and disposal of assets of liquidated banks handled by the Nigerian Deposit Insurance Corporation and, valuation of assets of public enterprises being privatised by The Bureau of Public Enterprises (BPE). Besides, the publication of a paper jointly authored by an actuary and a surveyor (Hager and Lord, 1985) raised a number of issues, which are embarrassing to the property profession. One section of the paper described a small survey of ten valuers who were asked to value two properties. The answers obtained ranged from $€ 630,000$ to $€$ 780,000 for an office property and $€ 450,000$ to $€$ 655,000 for a shop property.

Furthermore, Plattner (1990) in the United States, responding to similar criticisms, reported on two studies of appraised values to sales prices for real estate holding of large insurance company pension fund. The first study, which involved 294 properties sold from 1973 to 1987, indicated that the appraised values were on the average $5 \%$ below sales prices during the 14 -year period. A similar second study using data from 52 properties sold from 1973 to 1981 concluded that appraised values were $7 \%$ below sales prices during that period.

In response to these criticisms, Trott (1980; 1986), Brown (1985), Ferguson (1983), Drivers Jonas/IPD (1988 and 1990) and Ogunba (1997) maintained that valuations are a good proxy for prices and that valuers, despite the anecdotal evidence to the contrary, are doing a very good job of price estimation. This was challenged by Lizieri and Venmore Rowland (1991) who questioned the statistical methodology adopted in these studies. But, Brown (1992), in a rejoinder to Lizieri and Venmore-Rowland (1991) argued that the criticism failed to consider the economic foundation of valuation models and the importance of the information set.

Besides, Aluko (1998) has ably documented the methodological flaws in these studies and, therefore questioned their relevance to a low-information based environment like Nigeria. In this regard he further opined that the results of research of Ogunba (1997) entitled "A Study of Valuation and Pricing in the Residential Property Market in Lagos Metropolis" using one of these approaches appear inconclusive particularly that none of the valuers' sampled inspected the subject properties before expressing their opinions of value. This is important because failure to inspect the properties will restrict the amount of available information as will access to a limited database concerning comparable market transactions and investment yields.

A thicket of other studies (such as, Cole, Guilkey and Miles, 1986; Cullen, 1994; Matysiak and Wang, 1995; Blundell, 1995; Smith, 1986; Adair, Hutchison, MacGregor and Nanthakumaran, 1996; Graff and Young, 1999; and, Harvard, 2001) had demonstrated the in- 
ability of valuers to make effective estimations of value. And, it is evident in these studies, as in the previous ones, that given the imperfection of the trading environment and market structures, notwithstanding whether normal, boom or recession exists, it would be unreasonable to expect valuers to predict transaction price either precisely or exactly accurately. There are three possible explanations for variations and the later realised sale prices of properties (Aluko, 2000; and, Kummerow, 2002).

- First, the valuer may be negligent - there may be bias or faulty reasoning in the valuation. There may be flaws in method, data, assumptions or interpretation.

- Second, the observed sale may be a low probability outcome - the occasional improbable low or high sale that a distribution of possible sales could produce as a single outcome. The improbable, as a popular bumper sticker says in more graphic language, happens.

- Third, markets change so the possible sales prices distribution can vary through time. So valuation is a snap shot in time. Price indexes or other measures of price change may give some idea of this, a way of tracking market trends. Valuers should not be blamed for bad outcomes due to unforeseeable changes in market prices overtime. They should be paid to produce estimates of future price changes.

Furthermore, the tendency of point estimate to lead to imprecision in value estimate has been, also, due to a number of prevailing conditions in an imperfect property market. Professor Paul F. Wendt notes that

"although sales in the real estate market recommend themselves as prime evidence of values, the nonhomogeneity of real estate, variations of market activity and performance, differences in terms and conditions of sales, and questions of comparability add up to a formidable group of problems" (Wendt, 1956:267)

Implicit in the above statement is that typical motivation is not required of buyers and sellers in the adequate market, nor is it often found in the real estate market. Each seller presumably has his/her own sale motivations, tax and income situation, various opportunity costs associated with not selling (that is, under financial coercion), and particular degree of risk aversion, and, therefore, can be expected to have a unique sales strategy, asking price and bargaining position. Many of these arguments hold true in motivating also each potential buyer. This position attitude resort in widely varying estimates of market value for similar properties with different sellers or buyers. Price may be a function of a number of these factors affecting individual buyers and sellers. An example of these factors is time, in the sense that a seller able to wait for the best available offer will many times be able to command a higher price than the typical seller. The seller in a distressed sale tends to get less, not only because there is less time to reach perspective buyers but also because buyers sense the seller's urgency and reduce their offers accordingly. Unfortunately, the estimation of typical seller characteristics has received relatively little attention in valuation practice compared to assessment of typical buyer characteristics or of market conditions, even though it is equally important to an estimate of market value.

Also, the small number of transfers available, in a real estate market, for analysis, to a lack of identity in terms of sale among the properties used for comparison, and, as is typical in most real estate data analysis, to a lack of generally available knowledge regarding the terms of sales and the motivations of the parties involved build up random variations and mispricing errors in the value estimations for a subject property at a particular point in time. The situation holds the potential for large and often immediate profits for knowledgeable investors and, confusion on the part of estate surveyors and valuers and those they serve.

An estate surveyor and valuer's job is to make reasonable predictions about the value obtainable for a specific property or properties, based on patterns of behaviour observed in the market, the source of information on which all such predications are based. At the positive 
extreme, the valuer could constrain conditions to represent as closely as possible those of competitive market. This would result in estimates different from actual experience in individual cases, and even, in view of uncertainty and a certain degree of monopoly, which may be widespread in a market, that can affect sales prices. At the other extreme, the valuer can accept current market conditions as given, and a possible "speculative" market in which the valuer suspects eager buyers are tending to bid up sales prices above the long-term trend.

Nonetheless, one task of a valuer is the reduction of uncertainty in matters relating to real estate value. In this respect, Ratcliff (1975) reminds us that valuation is prediction, and like other predictions is made under conditions of uncertainty. This uncertainty can, perhaps, be measured in terms of the parameters of the data distribution form which market value is to be inferred. Other things being equal,

1. The wider the range of the data, the less likelihood that the value will fall at the mean or expected value.

2. The less the central tendency (e.g., the higher the coefficient of dispersion, which is the average dispersion from the mean divided by the mean), the less likelihood that the value will fall at or near the mean.

3. Conversely, where the distribution is skewed so that more than half the cases fall on one side or the other of the mean, the likelihood is that value will fall on the same side of the mean.

This can and should be expressed in probabilistic or statistical terms to provide range rather than point estimates, and be in tune with the conditions in the real estate market. Perhaps, with this approach, valuers will be able to deflect the claim by other professions to our domestic domain - valuation - or provide a shield against the intense scrutiny by academic, the media and the courts and the apparent lack of a coherent and consistent result from the valuation process, which has damaged the reputation of the valuation profession. Otherwise, the implication of inaccurate valu- ations is potentially considerable and may constrain property performance analysis, adversely influence the relevance and credibility of the valuer and, also result in damaging confidence in the property market

\section{REFINING VALUATION ESTIMATES AND PREDICTIONS}

From the foregoing, it is implicit that valuers only stand a reasonable chance of predicting the value, as point estimate, at which a property is likely to be exchanged if they can fix a point in time, fix the financing available, fix the motivations of a seller and a buyer, and determine the specific use to which a property may be put. But, in the process of estimating each of these variables, estate surveyors may also succeed in screening from their own and their clients' view all those matters that have a bearing on value in the event that any of the conditions that they have fixed are not borne out in fact.

How well an estate surveyor, therefore, serves his client depends in large measure on how skillfully he is able to work with and interpret limited data to arrive at reliable opinion of value in an imperfect market. Thus, in order to alleviate the inherent risks arising from market imperfections when predicting or estimating property value, valuers are advised to resolve to accept value spread in these cases through the development of a more analytically explicit definition of market value. First, that the estate surveyor must consider a "typical" seller (or a distribution of possible sellers) rather than the particular seller of the subject property. Second, that a distribution of potential buyers must be considered (possibly in conjunction with each possible seller), along with their distribution of probable uses and sales prices. Third, that actual, rather than idealized, market conditions must be recognised.

The above readily captured the idea of Ratcliff (1972a \& b) who advocated the concept of value as "most probable selling price" and of 
a property valuation as "an economic analysis under uncertain conditions that can be expressed only in terms of probability". Implied in the concept of most probable selling price is a range of possible prices, with the most probable selling price defined as the mean or median or mode within the range. Estate surveyor may serve his client better by delivering his answer within the framework of probability and range. As discussed previously, even the simplest of valuations there are likely to be a number of variables that the valuer must assess, such as, rent, yield, etc. yet, the valuer will not be $100 \%$ certain of the input figure. In effect, they will ascribe a degree of uncertainty to their belief in the input variable being "correct". This is a subjective probability and will vary according to the confidence level that they feel applies for that variable, in this case, either the property yield or the rent. It is therefore recommended that clients should be informed as to the amount of possible deviation and the magnitude of risk in the value (point) estimate through the adoption of any of the following statistical techniques.

Firstly, a probability distribution summarises the relationship between each possible value for a property and the probability of that value being correct. Depending on the scale of measurement, a probability distribution can be either "discrete" or "continuous". A discrete distribution is composed of individual elements that have a finite numerical value and specific probability of occurrence. A continuous distribution requires that there be an unlimited number of possible values and an infinitely small probability of any one value occurring. Property value can be treated as continuous because they are measured in the relatively small increment of N0.01. The normal distribution is a continuous probability distribution that can be used to describe the errors associated with property value estimates.

Secondly, Sensitivity Analysis and Scenarios could be adopted to qualify the opinion of value. There are many forms that sensitivity analysis can take, all of them examine the degree of capital value change caused by a change in one or more of the variables analysed. Sensitivity coefficients can then be determined showing capital sensitivity due to change in each variable in isolation and these capital sensitivity factor can be compared between property investments offered as a crude measure of risk. An alternative approach would be to take a range of possible values for each variable and combine them to give a range of capital values.

The use of scenarios is a simple extension of the sensitivity analysis described above. Rather than having a range of values for each variable giving a wide range of capital values of property, estimates are grouped to give say optimistic, realistic and pessimistic scenarios of capital value. This is likely to give a narrower band of values than the simplistic sensitivity analysis due to subjective probability being employed to limit the likely combinations of variables and hence of spread of results.

Finally, Monte Carlo Simulation has been used for many in non-property investment valuation and analysis and, has been put forward in the literature as a particularly useful approach in quantifying risks involved in the property investment valuation and analysis. There are two basic stages to Monte Carlo Simulation. The first involves estimating a range of values for each variable together with the likelihood or probability of each value occurring. The second stage involves undertaking property valuation and investment analysis with randomly selected values for each variable. This process is then repeated over and over again, each (computer) run producing an NPV or IRR (capital value). The following information would be shown as a result of numerous runs.

(i) Best estimate of NPWIRR/capital value

(ii) The standard deviation of NPV/IRR (capital value).

(iii) Range of NPV/IRR (capital value) and their probability of being achieved.

(iv) The cumulative probability of achieving or not achieving a certain NPV/IRR (capital value). 
Thus, a computer-simulation is a powerful analytic tool for assessing error and risk associated with a point estimate. It allows the valuer to examine the cumulative effect of the variance in many more variables than could be handled manually

\section{CONCLUSION}

We have demonstrated in this paper that estate surveyors in the country would serve their clients better by delivering their answers (opinions of value) within the framework of probability and range; property value estimates being imprecise in an uncertain, imperfect property market. The valuer, as the expert on the matter of value, has more than the point estimate to report. Unfortunately, however, answers framed in such concepts will only satisfy clients familiar with them. Clients come to estate surveyors because they do not know. For the buyers and sellers of real estate, large sums of money are involved, sums so large that the clients often do not trust their own ability to handle them wisely. They want expert advice. They want hard answers, not ranges and possibles and probables. For better or worse, there will always be clients looking for the one right answer and valuers willing to provide it. Those less enthusiastic about the use of these statistical techniques offer several other reasons. Many clients, notably lenders and government agencies, require a specific, unambiguous number. Another concern is that valuers are not now qualified to offer statistical analysis and to recommend its use would, in effect, require more education. A final argument is that statistical analysis cannot be used in a significant percentage of valuations.

The above arguments are less valid because valuation exists to meet a need in an uncertain, property market. And, there is the need for the adoption of statistical analysis to assist valuers in improving the accuracy and reliability of property value estimates or predictions, thus exposing clients to less risk and the attendant problems in real estate decision mak- ing process. For example, a loan officer may want a range of property values in order to assess the relative risk of obtaining repayment of the principal in the event of liquidation sale. Statistical analysis, through probability distributions and other explained above, provide useful information about confidence without such additional cost. Another plausible reason to recommend statistical techniques is that they provide protection for the estate surveyors and valuers at a time when professionals are increasingly subject to legal responsibility for their opinions. A single point estimate leaves little room for escape. One also might appeal to the well-established principle that valuation is a mixture of art and science and, as such, is understood to be imprecise. The use of statistical analysis is a direct recognition of this principle. Finally, statistical techniques and graphic analysis are not new to practicing estate surveyors, but the means of communicating them to clients is. The Continuing Professional Development and Research Committees of both The Institution and The Board will go a longway in assisting to overcome this situation. It seems, therefore, that estate surveyors should expand the scope of their services beyond the confines of the point estimate with a view to challenging the tradition and, providing opportunity for distinction in real estate valuation services for professional credibility.

\section{REFERENCES}

Adair, A., Hutchison, N., MacGregor, B., McGreal, S. and Nanthakumaran, N. (1996) An analysis of valuation variation in the U.K. Commercial Property Market, Property Valuation and Investment, 14(5), p. 34-47.

Ajayi, C.A. (1997) Towards New Directions for property valuation practice in Nigeria, The Estate Surveyor and Valuer, 20(1), p. 20-27.

Albritton, H.D. (1980) A critique of the prevailing definition of market value, Appraisal Journal, April, p. 199-205.

Albritton, H.D (1982) Controversies in Real property Valuation: A Commentary, AIREA, Chicago, 15 p. 
Aluko, B.T. (1998) A study of Accuracy of Mortgage Valuation for Institutional Lending in Nigeria, being an unpublished $\mathrm{Ph} . \mathrm{D}$. qualifying examination proposal submitted to the Department of Estate Management, Obafemi Awolowo University, Ile-Ife, Nigeria.

Aluko, B.T. (2000) A study of the appropriateness of mortgage valuation for institutional lending in Nigeria, an unpublished Ph.D. Thesis, Obafemi Awolowo University, Ile-Ife, Nigeria.

Blundell, G. (1995) Investment in property: A victim of the Quants? The Actuary, October, p. 12-13.

Bowles, G., McAllister, P., and Tarbert, H. (2001) An assessment of the impact of valuation error on property investment performance measurement, Journal of Property Investment and Finance, 19(2), p. 139-155.

Bretten, J. and Wyatt, P. (2001) Variance in commercial property valuations for lending purposes: an empirical study, Journal of Property Investment and Finance, 19(3), p. 267-282.

Brown, G.R. (1985) Property investment and performance measurement: a reply, Journal of Property Valuation and Investment, 4(1), p. 33-44.

Brown, G.R. (1991) Property investment and the capital markets, E \& FN Spon, London.

Brown, G.R. (1992) Valuation accuracy: developing the economic issues, Journal of Property Research, 9, p. 199-207.

Carsberg, B. (2002) Property Valuation: the Carsberg Report, Royal Institution of Chartered Surveyor, London.

Cole, R., Guilkey, D and Miles, M. (1986) Toward an assessment of the reliability of commercial appraisals, The Appraisal Journal, July, p. 53-58.

Colwell, P. (1979) A statistically oriented definition of market value, Appraisal Journal, January, p. 53-58.

Cullen, I. (1994) The accuracy of valuations revisited, The Cutting Edge 1994, The Royal Institution of Chartered Surveyors, London, p. 91-101.

Downs, A. (1991) Appraisal practices need revision, The Appraisal Journal, October, p. 454-458.

Drivers Jonas/IPD (1988), The Variance in Valuations, Drivers Jonas/Investment Property Databank, London.
Drivers Jonas/IPD (1990), The Variance in Valuations 1990 Update, Drivers Jonas/ Investment Property Databank, London.

Ferguson, J.T (1988) After-sale Evaluation: Appraisals or Justifications, The Journal of Real Estate Research, 3(1) spring, p. 19-26.

French, N. (1996) Investment Valuations: developments from the Mallinson Report, Journal of Property Valuation and Investment, 14(5), p. 48-58.

French, N. (1997) Market Information Management for Better Valuations: Concepts and Definitions of Price and Worth, Property Valuation and Investment, 15(5), p. 403-410.

French, N. (1998) Valuation - Word Play, Estate Gazette, January 17, p. 130-132.

French, N. and Gabriell, L. (2003) The uncertainty of valuation, Monograph, Department of Real Estate and Planning, The school of Business, The University of Reading, $17 \mathrm{p}$.

French, N. and Ward, C (1995) Valuation and Arbitrage, Journal of Property Research, 12(1), p. 1-11.

French, N. and Ward, C (1996) Applications of the Arbitrage Method of Valuation, Journal of Property Research, 13(1), p. 47-57.

Graff, R.A. and Young, M.S (1999) The magnitude of random appraisal error in commercial real estate valuation, Journal of Real Estate Research, 17(1/2), p. 33-54.

Greaves, M.J (1972) The Investment Method of Property Valuation and Analysis: An examination of some of its problems, unpublished Ph.D. Thesis, University of Reading, Reading.

Green well, W. and Co. (1976) A call for new Valuation Methods, Estate Gazette, 238(5780), p. 481-4.

Hager, D.P. and Lord, D.J. (1985) The property market, property valuations and property performance measurement, Institute of Actuaries, London.

Harvard, T (2001), Valuation reliability and valuer behaviour, Research paper Vol. 4, No 1, RICS, London, $46 \mathrm{p}$.

IVSC (2000), International Valuation Standard -Principles, Standards, and Applications and Performance Guidance, International Bureau, London, IVS Standards $1 \& 2$.

Kinnard, Jr., W.N. (2001) New Thinking In Appraisal Theory, The Appraisal Journal, July, 69(3), p. 235243. 
Korpacz, P.F. and Marchitelli, R. (1984) Market value: a contemporary perspective, The Appraisal Journal, October, p. 485-93.

Kummerrow, M. and Galfalvy, H. (2002) Error Tradeoffs in Regression Appraisal Methods, in Wang, Ko and Wolverton, M. eds., Real Estate Valuation Theory, American Real Estate Society, Kluwer Academic Publishers, Norwell, MA.

Kummerow, M. (2000) Thinking statistically about valuations, The Appraisal Journal, 68(3), p. 318-327.

Kummerow, M. (2002) A statistical definition of value, Research Monograph, Department of Land Economy and Valuation, Curtin University, Australia, $18 \mathrm{p}$.

Kummerow, M. (2003) Theory of Real Estate Valuation: An Alternative Way to Teach Real Estate Price Estimation Methods, Research Monograph, Department of Land Economy and Valuation, Curtin University, Australia, 29 p.

Lizieri, C. and Venmore-Rowland, P. (1991) Valuation accuracy: a contribution to the debate, Journal of Property Research, 8, p. 115-122.

Lusht, K.M. (1981) Data, the Appraisal Process, and the Market Value Definition, The Appraisal Journal, October, p. 534-46.

Lusht, KM. (1983) Most Probable Selling Price, The Appraisal Journal, July, p. 427-37.

Mallinson Report (1994), Commercial Property Valuations, Royal Institution of Chartered Surveyors, London.

Mallinson, M, and French, N. (2000) Uncertainty in Property Valuation: the nature and relevance of uncertainty and how it might be measured and reported, Journal of Property Investment and Finance, 18(1), p. 13-32.

Matysiak, G. and Wang, P. (1995) Commercial property market prices and valuations: analyzing the correspondence, Journal of Property Research, 12(3), p. 181-202.

Miles, WP. (1980) Error and risk in property value estimates, The Appraisal Journal, October, p. 540-548.

NIESV (1985) Guidance Notes on Property Valuation, 1"' Edition, The Nigerian Institution of Estate Surveyors and Valuers, Lagos.

Ogunba, O.A. (1997) A study of Valuation and Pricing Practices in the Residential Property Market in Lagos Metropolis, an unpublished M.Sc. Thesis, Obafemi Awolowo University, Ile-Ife.
Parker, D.R.R. (1998) Valuation Accuracy - an Australian Perspective, $4^{\text {th }}$ Pacific Rim Real Estate Society Conference, Perth, 19-21 January, 19 p. Peto, R., French, N. and

Bowman, G. (1996) Price and Worth: Developments in Valuation Methodology, Property Valuation and Investment, 14(4), p. 79-100. Platter, PH. (1990) A critique of recent Appraisal Thought, The Appraisal Journal, October, p. 180-189. Ratcliff, R.U. (1972a) Is there a New

School of Appraisal Thought, The Appraisal Journal, October, p. 522-538. Ratcliff, R.U. (1972b)

Valuation for Real Estate Decisions, Democratpress, Santa Cruz, 101 p.

Ratcliff, R.U. (1975) Appraisal is Market Analysis, Appraisal Journal, October, p. 485-490.

Ratcliff, R.U. (1979) Reading on Appraisal and its Foundation Economics, Landmark Research, Madison. RISC (2000) RISC Appraisal and

Valuation Manual, Royal Institution of Chartered Surveyors, London. Reenstierna, E.T (1983) Value Spread:

The Effects of Occupancy, Financing, and Buyer/Seller Motivation on Most Probable Selling Price, The Real Estate Appraiser and Analyst, summer, p. 39-43. Reenstierna, E.T. (1985) Alternatives to Point

Estimates, The Appraisal Journal, January, p. 115-126. Roberts, J.R. and Roberts, E. (1991)

The Myth about Appraisal, The Appraisal Journal, April, p. 212-220. Shlaes, J. (1984) The Market in market Value, The Appraisal Journal, October, p. 494-518. Shykes,

S. (1983) Property Valuation, Investment and Risk, in Chiddick, D. and Millington, A. (eds.), Land Management: New Directions, Spon, London. Smith, H.C. (1977) Value concepts as a source of disparity among appraisals, The Appraisal Journal, April, p. 203-209. Smith, H.C. (1986)

Inconsistencies in Appraisal Theory and Practice, The Journal of Real Estate Research, 1(1), fall, p. 1-17. The International Assets Valuation Standards Committee (TIAVSC) (2000), Introduction to the Guidance Notes and Background Papers, TIASVC, London. 
Trott, A. (1980) Property Valuation Methods: Interim Report, Polytechnic of the South Bank/ Royal Institution of chartered Surveyors, London.

Trott, A. (1986) ed., Property Valuation Methods: Research Report, Polytechnic of the South Bank/Royal Institution of Chartered Surveyors, London.

Vandell, K.D. (1982) Toward Analytically Precise Definitions of Market Value and Highest and Best Use, The Appraisal Journal, April, p. 253268.
Wendt, PR (1956) Real Estate Appraisal, Henry Holt, New York. Whipple, R.T.M. (1990) Valuations: a problem-solving imperative, New Zealand Valuers' Journal, June, p. 14-24. Whipple, R.T.M. (1995) Property Valuation and Analysis, Law Book Company, North Ryde, NSW. Wood, E. (1972) Property Investment - A Real Value

Approach, an unpublished Ph.D. Thesis, University of Reading, Reading. 